\title{
Peningkatan Layanan Umum Bagi Masyarakat Desa Banjarsari Kecamatan Cerme Kabupaten Gresik
}

\author{
Aristha Purwanthari S ${ }^{1}$, Taudlikhul Afkar ${ }^{2}$, Suharyanto ${ }^{3}$, I Ketut Surabagiarta ${ }^{4}$ \\ ${ }^{12}$ Program Studi Akuntansi, Fakultas Ekonomi, Universitas PGRI Adi Buana Surabaya \\ ${ }^{34}$ Program Studi Manajemen, Fakultas Ekonomi, Universitas PGRI Adi Buana Surabaya \\ E-mail : aristha@unipasby.ac.id
}

\begin{abstract}
ABSTRAK
Upaya peningkatan kesejateraan mayarakat desa dapat dilakukan melalui optimalisasi pembangunan Badan Usaha Milik Desa (BUMDes) untuk menuju desa mandiri dan kreatif. Pengelolaan BUMDes ini dilakukan Pemerintah Desa bersama masyarakat. Desa Banjarsari Kecamatan Cerme Kabupaten Gresik adalah desa yang berpotensi dari segi perekonomiannya yang hampir seluruh warganya menggantunkgan hidupnya dari faktor pertanian baik pertanian sawah seperti padi tebu dan jagung, hingga pertanian non sawah seperti tambak, kolam budidaya dan kebun buah-buahan. Hasil perikanan merupakan salah satu faktor yang paling mendominasi dimana banyak sekali pelaku-pelaku usaha perikanan seperti tambak bandeng dan beberapa kolam budidaya udang vanamei. Pada desa ini ditemukan bahwa belum optimalnya layanan umum bagi masyarakat, pemanfaatan aset desa, dukungan usaha produktif masyarakat, dan pengelolaan keuangan masyarakat. Akibatnya, masih banyak potensi desa yang belum dikelola dengan baik serta penyaluran dana serta pengelolaan dana ke masyarakat yang belum optimal. Hal ini dikarenak belum pahamnya masyarakat maupun perangkat desa bagaimana tahapan pengelolaan BUMDes yang baik dan benar. Berdasarkan permasalahan yang dihadapi oleh mitra, maka tim dosen fakultas ekonomi melakukan pengabdian dengan memberikan pelatihan pengelolaan BUMDes yang baik serta pengelolaan dan penyaluran dana desa yang efisien melalui beberapa tahapan di Desa Banjarsari Kecamatan Cerme Kabupaten Gresik.
\end{abstract}

Kata kunci : peningkatan layanan umum, pengelolaan dan dana desa, BUMDes

\begin{abstract}
The efforts to increase the access to the village are done through optimizing the development of village owned enterprises (BUMDes) to go to an independent and creative village. Management of the village owned enterprises is conducted by the village government along with the community. Village of Banjarsari District of Cerme Gresik is a village that has the potential in terms of its economy that almost all of its citizens rely on their life from farming factors either rice fields such as sugarcane and corn rice, to non-paddy farms such as ponds, aquaculture ponds and orchards. The result of fishery is one of the most dominating factors where there are many fishing business actors such as milkfish ponds and some ponds of shrimp vanamei. In this village, it is found that not optimal public services for the community, utilization of village assets, support of the Community's productive efforts, and the management of Community finances. Consequently, there are still many potential villages that have not been well managed and the distribution of funds and fund management to communities that are not optimal. It is well-grounded in the community as well as village devices how the management stages of BUMDes are good and correct. Based on the problems faced by the partners, the Faculty of Economics lecturers are devoted by providing good BUMDes management training and efficient management and distribution of village funds through several phases in the village of Banjarsari District Cerme Gresik Regency.
\end{abstract}

Keywords : Public service improvement, management and village funds, BUMDes 


\section{PENDAHULUAN}

Tujuan nasional dalam UUD 1945 adalah pada peningkatan kesejahteraan seluruh rakyat, bangsa, dan Negara yangdilakukan dengan cara pembangunan. Pembangunan desa perlu didukung masyarakat terutama yang bertempata tinggal di desa, dimana desa menjadi sangat penting dalam upaya pembangunan sehingga berpengaruh dalam usaha menciptakan stabilitas ekonomi, sosial, budaya, maupun politik secara nasional. Desa memiliki otonomi yang mendasar karena sebagai bagian wilayah kecamatan dan kabupaten, otonomi yang dimikili berupa otoritas untuk menurus dan mengatur kepetingan serta memanfaatkan potensi desa masing-masing. Otonomi tersebut menjadi bagian otonomi daerah yang ada pada Undang-Undang No 32 tahun 2004 tentang Penerintahan Daerah, dimana pada pasal 1 ayat (5) menjelaskan mengenai hak, wewenang, serta kewajiban daerah untuk mengarur serta mengurus daerahnya sendiri dalam urusan pemerintahan dan kepentingan masyarakat sesuai dengan peraturan perundang-undangan yang pada akhirnya disebut sebagai otonomi daerah. Tujuan otonomi daerah ini adalah untuk peningkatan pelayanan pada masyarakat, meningkatkan kemandiraian daerah, menumbuhkan perkembangan daerah adlam berbagai bidang, dan meningkatkan daya saing daerah. Hendarto (2002) tata kelola pemerintah masih belum optimal dalam memberikan pelayanan kepada publik. Hal ini juga didukung oleh Sirajjudin (2011) bahwa tata kelola pelayanan masyarakat yang baik apabila pemerintah menjalankan fungsi sesuai dengan prinsip tata kelola pemerintah, baik dalam hal administrasi, kualitas layanan untuk memenuhi kebutuhan masyarakat.

Desa Banjarsari Kecamatan Cerme Kabupaten Gresik merupakan desa yang memiliki potensi dari segi perekonomiannya hampir seluruh warganya menggantunkgan hidupnya dari faktor pertanian baik pertanian sawah seperti padi tebu dan jagung, hingga pertanian non sawah seperti tambak, kolam budidaya dan kebun buah-buahan. Hasil perikanan merupakan salah satu faktor yang paling mendominasi dimana banyak sekali pelaku-pelaku usaha perikanan seperti tambak bandeng dan beberapa kolam budidaya udang vanamei. Desa ini memliki visi mewujudkan masyarakat adil dan makmur serta pemerataan pembangunan di segala bidang dan misinya adalah meningkatkan peran serta masyarakat desa banjarsari dalam mengenali, menganalisis sekaligus mencari pemecahan terhadap masalah-masalah prioritas pembangunan desa banjarsari, terutama di bidang fisik prasarana, ekonomi dan sosial budaya.

Perwujudan visi serta misi desa Banjarsari tersebut terutama dalam bidang ekonomi, pemerintah melalui Undang-Undang No.6 Tahun 2014 tentang Desa menyarankan setiap desa agar membentuk dan memiliki badan usaha yang bermanfaat untuk memenuhi kebutuhan desa dan masyarakatnya, seperti kebutuhan pokok dan ketersediaan sumber daya desa dari sumber-sumber yang belum digunakan, serta ketersediaan sumber daya manusia agar dapat mengelola badan usaha di desa sebagai aset pertumbuhan perekonomian masyarakat desa. Upaya dapat dilakukan dengan cara optimalisasi dalam pembangunan Badan Usaha Milik Desa (BUMDes) 
untuk menjadi desa mandiri serta kreatif dalam peningkatan kesejahteraan masyarakat di daerah terutama di desa.

Mengelola BUMDes dapat dilakukan perangkat pemerintah desa dengan masyarakat desa setempat. Dalam mengelola BUMDes secara langsung dengan melibatkan masyarakat desa diperkirakan akan mampu mendorong pertumbuhan perekonomian masyarakat desa dalam udaha peningkatan kesejahteraan masyarakat, selain itu dapat juga dilakukan dengan tertib administrasi keuangan (Afkar, dkk 2018). Pemerintah akan memberikan bantuan dana bagi desa yang sudah membentuk dan memiliki BUMDes. Dimana usaha desa yang dioperasionalkan harus mempunyai keunggulan pada masingmasing desa sesuai dengan potensi dan kebutuhan desa-desa tersebut. Universitas PGRI Adi Buana (UNIPA) Surabaya melalui para civitas akademikanya yang wajib menjalankan "Tri Darma Perguruan Tinggi" mendampingi masyarakat desa Banjarsari Kecamatan Cerme Kabupaten Gresik mengoptimalkan fungsi dan peran Badan Usaha Milik Desa (BUMDes) bersama Tim Pengabdian Pada Masyarakat (PPM) Fakultas Ekonomi UNIPA Surabaya.

\section{METODE PELAKSANAAN}

Persoalan yang dihadapi oleh BUMDes di desa Banjarsari Kecamatan Cerme Kabupaten Gresik adalah kurangnya pengetahuan mengenai tahapan pengelolaan BUMDes yang baik, pengelolaan potensi desa yang baik serta penyaluran dan pengelolaan dana desa dengan efisien dan efektif. Pelaksanaan kegiatan pengabdian ini yaitu memberikan penyuluhan mengenai tahapan pengelolaan BUMDes yang baik dan penyaluran dana desa yang efektif dan efisien, tim terlebih dahulu memberikan pemahaman mengenai pentingnya peran serta masyarakat yang berkolaborasi dengan perangkat desa dalam pengelolaan BUMDes. Agar mitra dapat lebih memahami mengenai materi yang disampaukan saat penyuuhan selanjutnya melakukan praktek terkait tahapan pengelolaan BUMDes. Dalam pengelolaan BUMDes ada beberapa hal yang perlu dicermati, diantaranya perencanaan, pengamatan, penataan jenis usaha, pemeliharaan serta pelaporan hasil usaha. Tahap terakhir dalam pengabdian ini yaitu melakukan pendampingan kepada BUMDes dan masyarakat pelaku usaha penerima dana desa di Desa Banjarsari Kecamatan Cerme Kabupaten Gresik. Pendampingan dilakukan oleh tim pengabdian untuk mengetahui keberhasilan program yang ditawarkan.

\section{HASIL DAN PEMBAHASAN}

Kegiatan pengabdian kepada pelaku UMKM di Desa Banjarsari Kecamatan Cerme Kabupaten Gresik dilakukan selama 1 (satu) bulan. Hasil yang dihasilkan dalam kegiatan pengabdian ini adalah tahapan pengelolaan BUMDes. Adapun hasil pelatihan ini :

a. Pada tahapan pertama yaitu dilakukan perencaan mengenai penentuan jenis usaha apa yang akan dipilih. Pilihan usaha yang cocok dan yang dipilih merupakan jenis usaha yang paling berpotensi. Pada Desa Banjarsari Kecamatan Cerme Kabupaten Gresik potensi yang paling menonjol dan dapat dikembangkan adalah dari bidang perkebunan dan perikanan. Berdasarkan perencanaan usaha pengelolaan hasil 
bidang perkebunan berupa kripik jagung dan usaha pengelolaann hasil perikanan berupa abon ikan bandeng. Usaha lainnya yang dipilih untuk masuk sebagai potensi desa yaitu jenis usaha minuman prebiotik dari bermacam tanaman obat yang difermentasi dari jamur kombucha.

b. Pada tahapan kedua adalah pengamatan. Pada tahapan pengamatan yang perlu dipertimbangkan adalah seberapa besar potensi berkembangnya usaha yang telah ditentukan atau yang telah dipilih. Berdasarkan hasil pengamatan jenis makan dan minuman yang telah ditentukan dianggap akan mampu berkembang karena peminat makanan ringan maupun minuman olahan terutama yang berkhasiat bagi kesehatan tidak ada matinya.

c. Pada tahapan ketiga perlu dilakukan penataan jenis usaha. Penataan jenis usaha yang dimaksudkan adalah beragamnya jenis usaha yang perlu dikembangkan berdasarkan hasil perencaan, dimana pengelolaannya juga harus maksimal. Berdasarkan hasil penataan jenis usaha ada dua jenis usaha yang dikelola yaitu jenis usaha makanan ringan dan minuman kesehatan.

d. Pada tahapan keempat adalah pemeliharaan, dimana pemeliharaan ini ditujukan untuk terus melakukan pemeliharan terhadap badan usaha yang telah didirikan dan mengoptimalkan penyaluran dana yang telah didistribusikan pada setiap jenis usaha. Dana yang telah diberikan tidak dibiarkan begitu saja, tetapi harus ada pemeliharan dari segi keamanan sampai pada bertambahnya modal. Pada tahapan ini perlu dipastikan bahwa dana yang telah disalurkan telah digunakan dan dikelola sebagaimana mestinya sehingga ada hasil usaha yang dapat dipertanggungjawabkan. Bentuk pertanggungjawabnnya akan dilakukan pada tahapan berikutnya. Berdasarkan hasil pemeliharan

e. Pada tahapa kelima adalah pelaporan hasil usaha sebagai bentuk pertanggunjawaban. Pelaporan hasil dari usaha yang melibatkan pemimpin desa dan masyarakat harus transparansi mulai dari pemasukan sampai pengeluaran. Tahapan kelima ini tidak kalah pentingnya dengan tahapan lainnya. Perlu dilakukan pembukuan yang baik dan taat azas untuk mencegah adanya kesalahan dalam pencatatan dan pelaporan hasil usaha. Sebagai hasil dari pencatatan transaksi berikut pembukuan sederhana yang telah diterapkan untuk mencatatat transaksi di BUMDes Banjarsari Kecamatan Cerme Kabupaten Gresik terkait pengeluaran dan penerimaan kas:

Tabel 1. Pencatatan Pengeluaran Kas BUMDes Desa Banjarsari Kecamatan Cerme Kabupaten Gresik

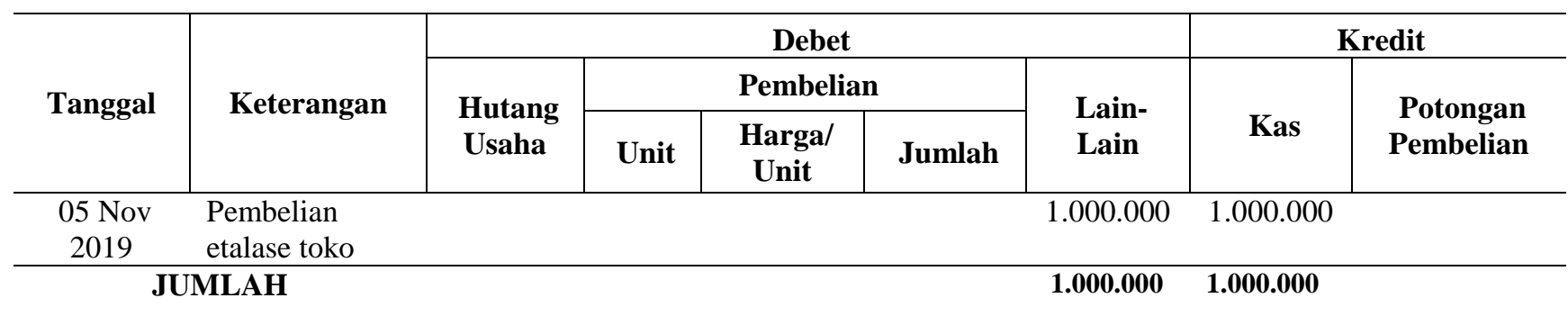


EKOBIS ABDIMAS

Jurnal Pengabdian Masyarakat
Volume 1, Nomor 1, Juni, 2020

E - ISSN : 2721-9933

Tabel 2. Pencatatan Penerimaan Kas BUMDes Desa Banjarsari Kecamatan Cerme Kabupaten Gresik

\begin{tabular}{|c|c|c|c|c|c|c|c|c|}
\hline \multirow{3}{*}{ Tanggal } & \multirow{3}{*}{ Keterangan } & \multicolumn{2}{|c|}{ Debet } & \multicolumn{5}{|c|}{ Kredit } \\
\hline & & \multirow[b]{2}{*}{ Kas } & \multirow{2}{*}{$\begin{array}{l}\text { Potongan } \\
\text { Penjualan }\end{array}$} & \multirow{2}{*}{$\begin{array}{c}\text { Piutang } \\
\text { Usaha }\end{array}$} & \multicolumn{3}{|c|}{ Penjualan Tunai } & \multirow[b]{2}{*}{ Lain-Lain } \\
\hline & & & & & Unit & $\begin{array}{c}\text { Harga/ } \\
\text { Unit }\end{array}$ & Jumlah & \\
\hline $\begin{array}{l}\text { 01 Maret } \\
2019\end{array}$ & $\begin{array}{l}\text { Diterima dana } \\
\text { hibah dari } \\
\text { Pemkab }\end{array}$ & \multicolumn{2}{|c|}{5.000 .000} & & & & & 5.000 .000 \\
\hline $\begin{array}{l}\text { 01 Maret } \\
2019\end{array}$ & $\begin{array}{l}\text { Pelunasan } \\
\text { taguhan Toko } \\
\text { Agung }\end{array}$ & \multicolumn{2}{|c|}{400.000} & & 100 & 4.000 & 400.000 & \\
\hline \multicolumn{2}{|c|}{ JUMLAH } & 5.400 .00 & & & & & 400.000 & 5.000 .000 \\
\hline
\end{tabular}

Dalam pelaksanaan kegiatan pengabdian ini, mitra diberikan pelatihan mengenai penyusunan laporan keuangan mulai dari pencatatan transaksi kas, menyusun laporan laba rugi, dan menyusun laporan posisi keuangan. Pencatatan transaksi kas dilakukan baik kas masuk untuk mencatat transaksi penerimaan dana hibah dan penerimaan (tunai) atas penjualan serta kas keluar untuk pembayaran utang maupun beban. Selain itu materi terakhir terkait pelatihan keuangan adalah pelatihan penghitungan harga pokok penjualan

Dalam pelaksanaan kegiatan juga diberikan pelatihan pemanfaatan teknologi melalui penerapan microsoft excel untuk membantu mempermudah melakukan pencatatan transaksi maupun pelaporan keuangan. Selama 1 bulan, mitra telah mampu untuk membuat laporan pengeluaran dan penerimaan kas, laporan dalam pembelian dan penjualan, laporan neraca atau posisi keuangan, dan laporan laba rugi serta mampu untuk menetapkan harga pokok penjualan.

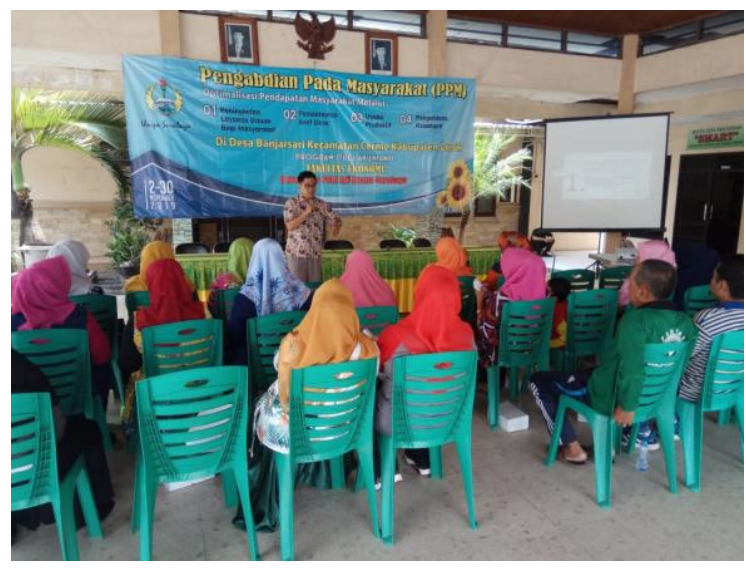

Gambar 1. Penyampaian Materi oleh Tim 


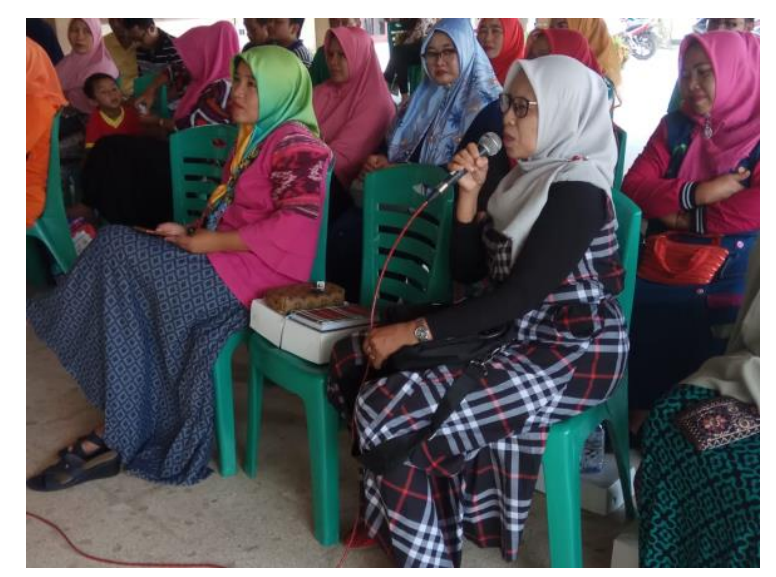

Gambar 2. Sesi Diskusi dengan Mitra

\section{DAMPAK DAN MANFAAT KEGIATAN}

Hasil yang telah dicapai dengan adanya kegiatan pengabdian yang telah dilakukan oleh tim adalah peningkatan kemampuan pengelolaan BUMDes yang baik dan penyaluran dana desa yang efektif dan efisien

\section{SIMPULAN}

Setelah dilakukannya pelatihan dan pendampingan kepada BUMDes Desa Banjarsari, dapat disimpulkan bahwa mitra telah mampu melakukan penerapan tahapan peningkatan layanan umum di desa khususnya BUMDes serta penyusunan laporan keuangan secara mandiri. Adapun saran kegiatan ini adalah mitra dapat konsisten menerapkan tahapan dalam peningkatan layanan umum serta melakukan pencatatan dan pelaporan akuntansi.

\section{UCAPAN TERIMA KASIH}

Tim pengabdian Fakultas Ekonomi mengucapkan terima kasih atas pendanaan internal dari LPPM Universitas PGRI Adi Buana Surabaya, sehingga program-program yang ditawarkan oleh tim kepada mitra (BUMDes) berjalan dengan lancar serta mitra dapat memperoleh manfaat atas program yang ditawarkan yang dilakukan oleh tim pengabdian.

\section{DAFTAR PUSTAKA}

Afkar, Taudlikhul., Waryanto, Bambang R., Subakir., Sugijanto., Istikhoroh, Isti., Fauziyah. (2018). Upaya Peningkatan Penghasilan UKM dengan Tertib Administrasi Keuangan di Desa Kenongo Kecamatan Tulangan Sidoarjo. Asian Journal of Innovation and Entrepreneurship. Vol. 3, No. 3, hal 351-357

Hendarto, Agung dan Nizar Suhendra. (2002). Good Governance dan Penguatan Institusi Daerah, Masyarakat Transparansi Indonesia (MTI), Jakarta 
Sirajjudin, Didik Sukriono dan Winardi. (2011). Hukum Pelayanan Publik Berbasis Partisipasi dan Keterbukaan Informasi, Setara Press (Kelompok Insrans Publishing), Malang

Undang-Undang Republik Indonesia Nomor 32 Tahun 2004 Tentang Pemerintahan Daerah

Undang-Undang Republik Indonesia Nomor 6 Tahun 2014 Tentang Desa 